\title{
ATP and purinergic receptor-dependent membrane traffic in bladder umbrella cells
}

\author{
Edward C.Y. Wang, ${ }^{1,2}$ Jey-Myung Lee, ${ }^{1}$ Wily G. Ruiz, ${ }^{1}$ \\ Elena M. Balestreire,1,2 Maximilian von Bodungen,, ${ }^{1}$ Stacey Barrick,1 \\ Debra A. Cockayne, ${ }^{3}$ Lori A. Birder, ${ }^{1}$ and Gerard Apodaca ${ }^{1,2}$ \\ ${ }^{1}$ Renal-Electrolyte Division and Laboratory of Epithelial Cell Biology and 2Department of Cell Biology and Physiology, \\ University of Pittsburgh, Pittsburgh, Pennsylvania, USA. ${ }^{3}$ Roche Palo Alto, Palo Alto, California, USA.
}

\begin{abstract}
The umbrella cells that line the bladder are mechanosensitive, and bladder filling increases the apical surface area of these cells; however, the upstream signals that regulate this process are unknown. Increased pressure stimulated ATP release from the isolated uroepithelium of rabbit bladders, which was blocked by inhibitors of vesicular transport, connexin hemichannels, ABC protein family members, and nucleoside transporters. Pressure-induced increases in membrane capacitance (a measure of apical plasma membrane surface area where $1 \mu \mathrm{F} \approx 1 \mathrm{~cm}^{2}$ ) were inhibited by the serosal, but not mucosal, addition of apyrase or the purinergic receptor antagonist PPADS. Upon addition of purinergic receptor agonists, increased capacitance was observed even in the absence of pressure. Moreover, knockout mice lacking expression of $\mathrm{P}_{2} \mathrm{X}_{2}$ and/or $\mathrm{P} 2 \mathrm{X}_{3}$ receptors failed to show increases in apical surface area when exposed to hydrostatic pressure. Treatments that prevented release of $\mathrm{Ca}^{2+}$ from intracellular stores or activation of PKA blocked ATP $\gamma$ S-stimulated changes in capacitance. These results indicate that increased hydrostatic pressure stimulates release of ATP from the uroepithelium and that upon binding to $\mathrm{P} 2 \mathrm{X}$ and possibly $\mathrm{P} 2 \mathrm{Y}$ receptors on the umbrella cell, downstream $\mathrm{Ca}^{2+}$ and PKA second messenger cascades may act to stimulate membrane insertion at the apical pole of these cells.
\end{abstract}

\section{Introduction}

ATP is a multifunctional biological molecule that acts not only intracellularly as the primary source of energy for living cells but also extracellularly as a signaling molecule that regulates diverse cellular processes including synaptic transmission, nociception, ion transport, apoptosis, secretion, and bladder contraction (1-3). ATP is abundant in the cell cytoplasm (3-5 mM) (1) and can be released extracellularly by several mechanisms including exocytosis of ATP-containing vesicles $(1,4-7)$; transport via connexin hemichannels (8); or transport by nucleoside transporters, a process that may be regulated by the cystic fibrosis transmembrane conductance regulator (CFTR) (9-12). Extracellular ATP binds to cell-surface purinergic receptors of the P2 class including the 8 transmembrane domain-containing $\mathrm{P} 2 \mathrm{Y}$ receptors $\left(\mathrm{P} 2 \mathrm{Y}_{1}, \mathrm{P} 2 \mathrm{Y}_{2}\right.$, $\mathrm{P}_{2} \mathrm{Y}_{4}, \mathrm{P}_{2} \mathrm{Y}_{6}, \mathrm{P}_{2} \mathrm{Y}_{8}, \mathrm{P}_{2} \mathrm{Y}_{11}, \mathrm{P}_{2} \mathrm{Y}_{12}$, and $\mathrm{P} 2 \mathrm{Y}_{13}$ isoforms) (13) and the ligand-gated ion-conducting $\mathrm{P} 2 \mathrm{X}$ receptors, of which 7 receptor subunits have been described $\left(\mathrm{P} 2 \mathrm{X}_{1}-\mathrm{P} 2 \mathrm{X}_{7}\right)(14)$.

Purinergic signaling pathways may play an important role in regulating normal urinary bladder function. For example, $\mathrm{P} 2 \mathrm{X}_{1}$ receptors are found on the detrusor smooth muscle $(15,16)$, and there is evidence that ATP may regulate bladder contractility (17-20). Furthermore, receptors containing the $\mathrm{P}_{2} \mathrm{X}_{3}$ receptor subunit are found on pelvic afferent nerves that innervate the urinary bladder (20) and may function to sense bladder filling and storage $(20,21)$. The bladder epithelium releases ATP in response

Nonstandard abbreviations used: ATP $\gamma \mathrm{S}$, adenosine $5^{\prime}$-[ $\gamma$-thio] triphosphate; BFA, brefeldin A; CFTR, cystic fibrosis transmembrane conductance regulator; $\alpha, \beta$-meATP, $\alpha, \beta$-methylATP; 2MeSADP, 2-(methylthio)-ADP; 2MeSATP, 2-(methylthio)-ATP; MESNA, 2-mercaptoethanesulfonic acid; PPADS, pyridoxalphosphate-6-azophenyl$2^{\prime}, 4^{\prime}$-disulfonic acid.

Conflict of interest: Lori Birder received support from Roche Palo Alto during 2004.

Citation for this article: J. Clin. Invest. 115:2412-2422 (2005).

doi:10.1172/JCI24086. to mechanical stimuli $(20,22)$, and it is hypothesized that ATP released from the serosal surface of the uroepithelium during bladder filling stimulates $\mathrm{P} 2 \mathrm{X}_{3}$-containing receptors on suburothelial sensory nerve fibers, thus signaling information about urinary bladder filling (21). The uroepithelium also expresses multiple purinergic receptors, including all $7 \mathrm{P} 2 \mathrm{X}$ receptor subunits as well as $\mathrm{P} 2 \mathrm{Y}_{1}, \mathrm{P}_{2} \mathrm{Y}_{2}$, and $\mathrm{P}_{2} \mathrm{Y}_{4}$ receptors (15-17, 23-25). However, the nature of the functional receptors and their role in this tissue remain unknown.

An important function of the uroepithelium is to maintain a permeability barrier that can adjust to large variations in urine volume as the bladder fills and empties. At the cellular level, filling may be accommodated, in part, by exocytosis and fusion of a subapical pool of discoidal/fusiform-shaped vesicles with the apical plasma membrane of the superficial umbrella cells, which thereby increases mucosal surface area $(26,27)$. The increase in apical surface area is modulated by concomitant endocytosis that, in combination with vesicle exocytosis, balances the change in apical surface area (26). Studies thus far have defined cAMP and intracellular $\mathrm{Ca}^{2+}$ as downstream signaling molecules that stimulate filling-induced discoidal/fusiform vesicle exocytosis $(26,28)$. However, nothing is known about the upstream events that are responsible for initiating these and possibly other second messenger cascades. In this report, we provide evidence that ATP released from the uroepithelium or surrounding tissue acts as a trigger for discoidal/fusiform vesicle exocytosis and membrane recovery through signaling at uroepithelial receptors containing $\mathrm{P} 2 \mathrm{X}_{2}, \mathrm{P} 2 \mathrm{X}_{3}$, and possibly $\mathrm{P} 2 \mathrm{Y}$ receptor subunits. These observations suggest a non-neuronal role for $\mathrm{P} 2 \mathrm{X}_{3}$-containing receptors and support the idea that in addition to stimulating sensory afferent nerves, another sensory role for ATP within the urinary bladder is to act as an upstream signal to regulate membrane traffic in the umbrella cell layer. These findings may also provide 
A

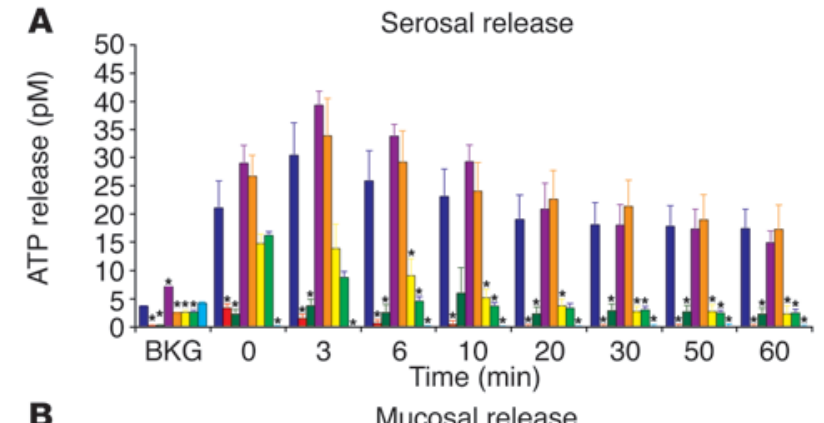

B

Mucosal release

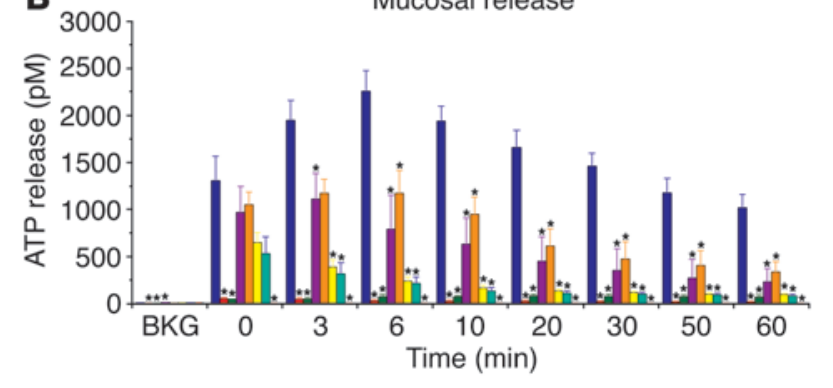

C

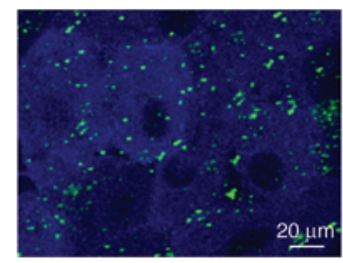

D

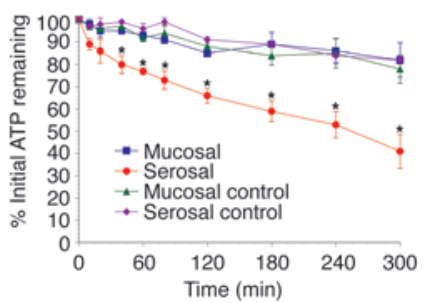

\section{Figure 1}

ATP localization, release, and hydrolysis in uroepithelium. (A and B) Pressure-induced release of ATP from the serosal (A) or mucosal (B) surfaces of rabbit uroepithelium. The epithelial tissue was mounted in modified Ussing stretch chambers, equilibrated, and pretreated with the indicated drug 15 minutes before the start of the experiment. ATP release was measured just prior to the start of the experiment (background [BKG]), immediately following the rise in hydrostatic pressure $(t=0)$, and $3,6,10,20,30,50$, and 60 minutes after the pressure was raised. Results are expressed as mean $\pm \operatorname{SEM}(n \geq 3)$. *Statistically significant difference $(P<0.05)$ relative to the appropriate control. (C) Rabbit uroepithelium was incubated with $5 \mu \mathrm{M}$ quinacrine for 30 minutes at room temperature, subsequently labeled with FM4-64 (to label cell membranes), and then imaged using a confocal microscope. The image is a projection of the Z series. Quinacrine staining is shown in green, and FM4-64 staining is shown in blue. (D) ATP $(50 \mu \mathrm{M})$ was added to the mucosal or serosal hemichamber (labeled "Mucosal" and "Serosal," respectively) of tissue mounted in Ussing stretch chambers. In control reactions, tissue was replaced with plastic film (labeled "Mucosal control" and "Serosal control"). At the designated time points, samples were taken, and the ATP concentration remaining in the hemichamber was measured. Results are expressed as mean \pm SEM $(n \geq 3)$. *Statistically significant difference $(P<0.05)$ relative to the appropriate control.

further insight into the physiological regulation of membrane traffic in other mechanically sensitive epithelia, including those that line the airways, gut, and the urogenital tract.

\section{Results}

Changes in bydrostatic pressure stimulate ATP release from both surfaces of the uroepithelium. Earlier studies indicated that the uroepithelium releases ATP in response to experimental distention, electrical stimulation, osmotic stress, and treatment with amiloride $(7,20,22,29)$. We investigated whether isolated uroepithelium, mounted in Ussing stretch chambers, released ATP when exposed to increased hydrostatic pressure. In our system, the mucosal hemichamber faced the apical surface of the umbrella cell layer, while the serosal hemichamber faced the connective tissue underlying the multilayered uroepithelium. In the absence of pressure changes (designated as background [BKG] in Figure 1, A and B), the concentration of ATP in the mucosal and serosal hemichambers was low $(2.9 \pm 2.2 \mathrm{pM})$. However, the concentration of ATP in the hemichambers significantly increased immediately after the pressure was increased $(t=0)$, peaked after 3-6 minutes, and then remained elevated for at least 60 minutes after stimulation (Figure 1, A and B). The amount of ATP released into the mucosal hemichamber was approximately 50 -fold greater than that released into the serosal hemichamber (Figure 1, A and B). Control experiments confirmed that increased pressure did not cause substantial release of the cytoplasmic protein lactate dehydrogenase (data not shown), which indicated that ATP release was not the result of plasma membrane damage.

To assess the mechanism of ATP release from the uroepithelium, we determined the effects of pharmacological agents known to modify ATP release in other cell types. The general secretion inhibitor brefeldin A (BFA) dramatically reduced the release of ATP into the serosal and mucosal hemichambers (Figure 1, A and B). Anandamide, which can block release of ATP through connexin hemichannels (8) but also acts as a ligand for cannabinoid and transient receptor potential vanilloid 1 (TRPV1) channels $(30,31)$, markedly reduced serosal and mucosal release of ATP (Figure 1, A and B). In contrast, flufenamic acid, which also inhibits ATP transport through connexin hemichannels $(8,32)$, impaired mucosal but not serosal release of ATP (Figure 1, A and B). Glibenclamide, a blocker of some ion $\mathrm{ABC}$ proteins such as the CFTR and sulfonylurea receptors $(33,34)$, had no significant effect on serosal ATP release but did cause a decrease in mucosal ATP release (Figure 1, A and B). Verapamil, an inhibitor of several additional $\mathrm{ABC}$ proteins (35) and L-type $\mathrm{Ca}^{2+}$ channels (36), and dipyridamole, an inhibitor of nucleoside transporters (37), caused significant inhibition of both serosal and mucosal ATP release (Figure 1, A and B). No ATP release was observed when the uroepithelium was first removed by gentle scraping before the underlying submucosa was mounted and exposed to pressure (Figure 1, A and B), which confirms that the uroepithelium was the source 

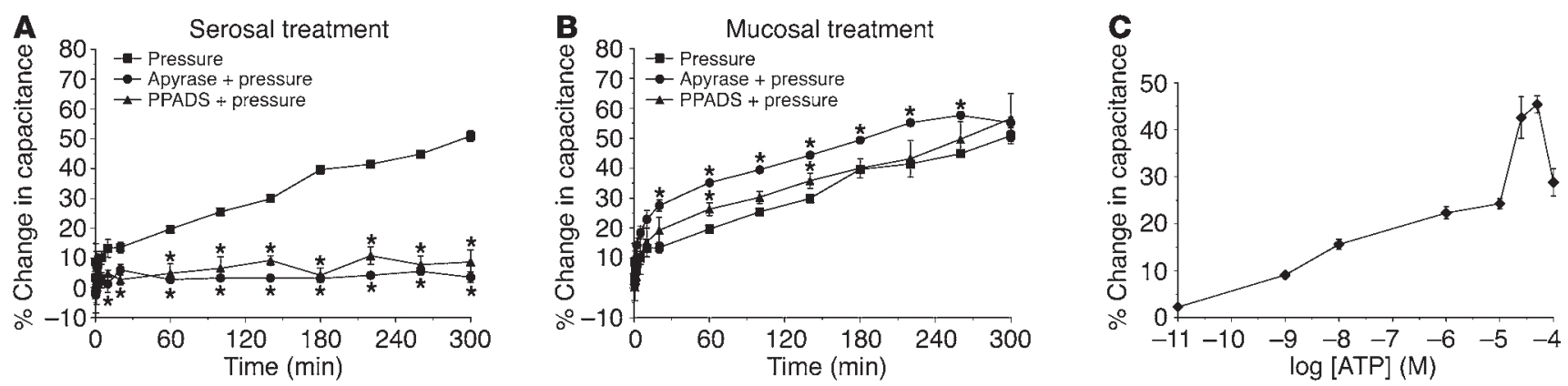

Figure 2

Effects of ATP, apyrase, and PPADS on changes in membrane capacitance. (A and B) Isolated rabbit uroepithelial tissue was exposed to pressure alone (Pressure), pressure and $0.4 \mathrm{U} / \mathrm{ml}$ apyrase (Apyrase + pressure), or pressure and $100 \mu \mathrm{M}$ PPADS (PPADS + pressure). PPADS and apyrase were added to either the serosal (A) or mucosal (B) surfaces of the tissue. The mean changes in capacitance \pm SEM $(n \geq 3)$ are shown. *Statistically significant difference $(P<0.05)$ relative to the samples treated with pressure alone. (C) ATP (at the indicated concentration) was added to the serosal surface of isolated rabbit uroepithelium without pressure stimulus. The mean change ( \pm SEM) in capacitance at 300 minutes after addition of ATP was recorded $(n \geq 3)$ and plotted versus the log of the ATP concentration.

of ATP release. When the uroepithelium was incubated with quinacrine, a membrane-permeant fluorescence dye that interacts with peptide-bound ATP in vesicles $(6,32)$, large punctate structures, possibly exocytic vesicles, were observed in the cytoplasm of the outer umbrella cell layer (Figure 1C).

In many tissues, ATP is rapidly degraded by the action of ectonucleotidases/exonucleotidases (38). To determine the extent of ATP hydrolysis in the bladder mucosa, we added $50 \mu \mathrm{M}$ ATP to the mucosal and serosal hemichamber of mounted bladder tissue and measured the amount of ATP remaining in the hemichambers over time. After 5 hours, approximately $60 \%$ of ATP added to the serosal hemichamber was degraded (Figure 1D), while approximately $20 \%$ of ATP added to the mucosal hemichamber was hydrolyzed in the same time period. The rate of ATP hydrolysis at the mucosal surface was not significantly different than the rate of ATP hydrolysis that occurred when the bladder mucosa was substituted with a piece of plastic wrap. Under these conditions, approximately $20 \%$ of ATP added to either hemichamber was degraded (Figure 1D).

Together, the inhibition of ATP release by BFA and the localization of ATP to vesicular structures were consistent with vesicular release of ATP from the uroepithelium. However, the pharmacological analysis indicated that release of ATP may also occur through other mechanisms including connexin hemichannels, $\mathrm{ABC}$ proteins, and nucleoside transporters. Furthermore, the mechanism(s) of ATP release from the 2 tissue surfaces was not identical, as flufenamic acid and glibenclamide had differential effects on mucosal and serosal ATP release. Finally, we observed that significant ATP hydrolysis occurred at the serosal surface of the uroepithelium, which indicated the presence of ectonucleotidases/exonucleotidases at this surface.

ATP stimulates umbrella cell apical membrane dynamics. If extracellular ATP is a signal for pressure-induced exocytosis in umbrella cells, then depletion of extracellular ATP should inhibit exocytosis, while addition of exogenous ATP might promote exocytosis even in the absence of pressure. In the isolated uroepithelial tissue preparation used in this analysis, changes in membrane capacitance primarily reflect changes in the apical surface area of the umbrella cell layer (where $1 \mu \mathrm{F} \approx 1 \mathrm{~cm}^{2}$ of area) and correlate well with other measures of apical exocytosis in umbrella cells $(26,28,39)$. As shown in Figure 2, A and B, elevation of pres- sure caused an increase in membrane capacitance in untreated uroepithelium up to approximately $55 \%$ after 300 minutes. The addition of the membrane-impermeant exonucleotidase apyrase to the serosal hemichamber almost completely inhibited pressure-induced changes in capacitance (Figure 2A). In contrast, when apyrase was added to the mucosal hemichamber, the initial changes in capacitance were greater than those of tissue exposed to pressure alone (Figure $2 \mathrm{~B}$ ). This possibly reflects the generation of ATP intermediates such as ADP, AMP, or adenosine that could enhance pressure-induced changes in capacitance in a mucosa-dependent manner. Similar results were obtained when hexokinase and its substrate glucose were used to deplete extracellular ATP (data not shown).

To determine whether exogenous ATP could directly promote exocytosis in bladder umbrella cells, we added $50 \mu \mathrm{M}$ ATP to the serosal or mucosal hemichamber of tissue not exposed to pressure and measured changes in membrane capacitance for up to 300 minutes.

\section{Table 1}

Effect of purinergic receptor agonists on changes in membrane capacitance

$\begin{array}{lcc}\text { Agonist } & \begin{array}{c}\% \text { Change in capacitance } \\ \text { upon serosal addition }\end{array} & \begin{array}{c}\% \text { Change in capacitance } \\ \text { upon mucosal addition }\end{array} \\ \text { No treatment } & 1.7 \pm 0.8 & 1.7 \pm 0.8 \\ \text { ATP } & 43.6 \pm 3.3 & 33.1 \pm 1.2 \\ \text { ATP } \gamma S & 55.8 \pm 5.8 & 0.6 \pm 1.2 \\ \text { 2MeSATP } & 51.0 \pm 6.0 & 19.9 \pm 0.8 \\ \text { BzATP } & 39.8 \pm 0.9 & 34.4 \pm 1.9 \\ \alpha, \beta-m e A T P & 16.3 \pm 1.7 & 23.4 \pm 5.0 \\ \text { 2MeSADP } & 52.7 \pm 3.8 & - \\ \text { ADP } & 25.3 \pm 3.1 & 18.1 \pm 0.3 \\ \text { UTP } & 2.5 \pm 1.5 & 42.9 \pm 1.3 \\ \text { UDP } & 29.7 \pm 0.7 & 35.9 \pm 0.3 \\ \text { Adenosine } & 42.7 \pm 3.0 & 18.1 \pm 0.3 \\ \text { AMP } & 34.6 \pm 2.9 & 37.6 \pm 0.8 \\ & & \end{array}$

Agonists were added at a final concentration of $50 \mu \mathrm{M}$ to the mucosal or serosal surface of rabbit uroepithelial tissue, and the percent increase in capacitance was measured after 5 hours of agonist treatment in the absence of pressure. Data are mean $\pm \operatorname{SEM}(n \geq 3)$. BzATP, benzoyl ATP. 

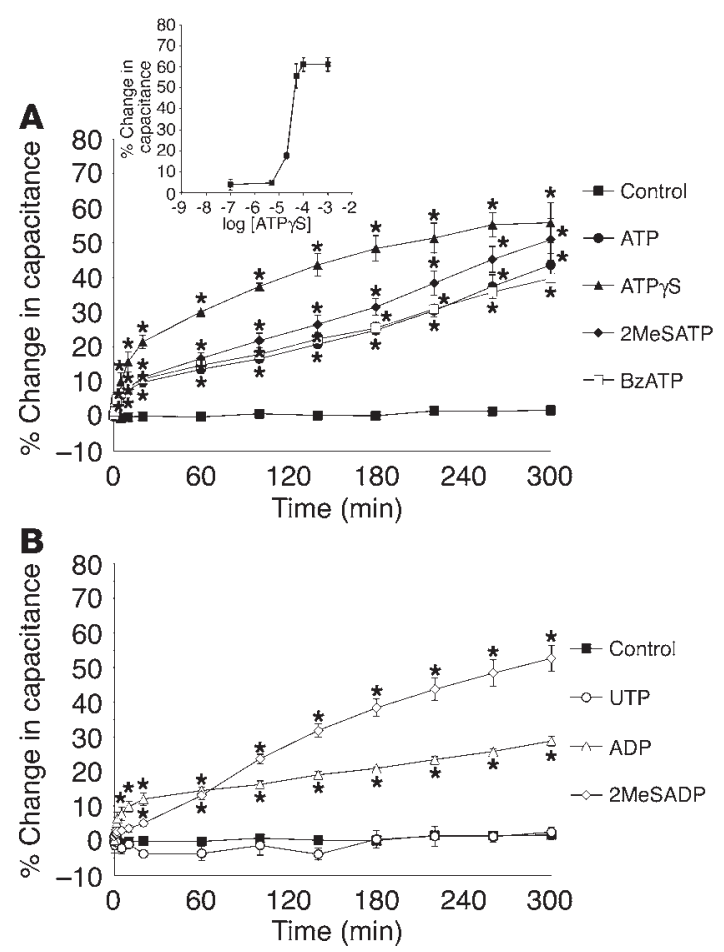

As shown in Figure 2C and Table 1, serosal addition of ATP stimulated a significant, approximately $44 \%$ increase in membrane capacitance, while mucosal addition stimulated an increase of approximately $33 \%$. Although the largest change in membrane capacitance was observed at $50 \mu \mathrm{M}$ ATP, an increase in capacitance was observed at even $1 \mathrm{nM}$ ATP (Figure 2C). The change in capacitance in response to $100 \mu \mathrm{M}$ ATP was less than that in response to $50 \mu \mathrm{M}$ ATP, which indicates that this concentration of ATP may activate an inhibitory pathway(s). We also sought to determine whether a short pulse of ATP was sufficient to generate maximal capacitance changes. Fifty micromolar ATP was added to the serosal surface of the tissue for 15 minutes and removed by washing over a 5-minute period, and the tissue was incubated for an additional 300 minutes in the absence of ATP. Under these conditions, there was a linear increase in capacitance that peaked at approximately $20 \%$ after 5 hours (data not shown), which indicates that maximal ATP responses required chronic stimulation with ATP. Taken together, these data indicate that while capacitance changes can be stimulated by addition of ATP to either surface of the uroepithelium, pressure-induced changes in capacitance were selectively inhibited by loss of ATP at the serosal surface.

To determine whether purinergic receptors were involved in ATP-dependent changes in membrane capacitance, we tested the effects of the nonselective $\mathrm{P} 2$ receptor antagonist pyridoxalphosphate-6-azophenyl-2',4'-disulfonic acid (PPADS) and various $\mathrm{P} 1$ and $\mathrm{P} 2$ receptor agonists $(2,14)$. Consistent with the data for apyrase presented above, pressure-induced changes in capacitance were almost completely blocked when PPADS was added to the serosal hemichamber, but there was little effect when it was added to the mucosal hemichamber (Figure 2, A and B). Since PPADS can block both P2X and P2Y receptors, the effect of various P2 receptor agonists was examined to broadly define the class of receptor(s) involved. Adenosine $5^{\prime}$-[ $\gamma$-thio]triphosphate (ATP $\left.\gamma \mathrm{S}\right)$

\section{Figure 3}

Modulation of membrane capacitance by serosal addition of purinergic receptor agonists. (A and $\mathbf{B}$ ) ATP or the following ATP agonists were added at a final concentration of $50 \mu \mathrm{M}$ to the serosal surface of isolated rabbit uroepithelium without exposure to pressure changes: ATP $\gamma$, 2MeSATP, benzoyl ATP (BzATP), UTP, ADP, or 2MeSADP. The inset in $\mathbf{A}$ shows a dose-response curve for the change in capacitance recorded 300 minutes after addition of the specified concentration of ATP $\gamma$ S. Data are shown as mean changes in capacitance \pm SEM $(n \geq 3)$. *Statistically significant difference $(P<0.05)$ relative to untreated control preparations.

and 2-(methylthio)-ATP (2MeSATP), relatively potent P2X agonists (40) but also agonists of $\mathrm{P}_{2} \mathrm{Y}_{1}$ receptors (41), caused significant increases in membrane capacitance of approximately $56 \%$ and approximately $51 \%$, respectively, when added to the serosal surface of non-pressure-treated uroepithelium (Figure 3A and Table 1). Compared with the other agonists tested, ATP $\gamma \mathrm{S}(50 \mu \mathrm{M})$ resulted in the greatest change in capacitance (Table 1), and the $\mathrm{EC}_{50}$ of $\mathrm{ATP} \gamma \mathrm{S}$ was found to be approximately $27 \mu \mathrm{M}$ in this system (Figure $3 \mathrm{~A}$, inset). In contrast, $2 \mathrm{MeSATP}$ and ATP $\gamma \mathrm{S}$ had modest $(20 \%)$ or no $(<1 \%)$ effects, respectively, when added to the mucosal surface (Table 1). Benzoyl ATP (BzATP), an agonist of P2X $, \mathrm{P}_{2} \mathrm{X}_{3}, \mathrm{P} 2 \mathrm{X}_{2 / 3}$, and $\mathrm{P} 2 \mathrm{X}_{7}$ receptors $(14,40)$, was as effective as ATP at stimulating increases in capacitance when added to either the serosal ( 40\%) or mucosal ( $34 \%)$ surface (Figure $3 \mathrm{~A}$ and Table 1$)$. In contrast, the $\mathrm{P} 2 \mathrm{X}_{1^{-}}, \mathrm{P} 2 \mathrm{X}_{3^{-}}$, and P2X $2 / 3^{-}$-selective agonist $\alpha, \beta$-methylATP $(\alpha, \beta$ meATP) induced only modest capacitance changes when added to either the serosal $(\sim 16 \%)$ or the mucosal $(\sim 23 \%)$ surface (Table 1$)$.

ADP and UTP, general agonists for P2Y receptors $(2,41)$, had small $(\sim 25 \%)$ or no $(-2.5 \%)$ effects on capacitance when added serosally, while 2-(methylthio)-ADP (2MeSADP), a potent agonist for several P2Y receptors (41), caused a significant stimulation of approximately 53\% (Figure 3B and Table 1). Marked increases in capacitance were seen when UTP ( 43\%) and UDP ( 36\%) were

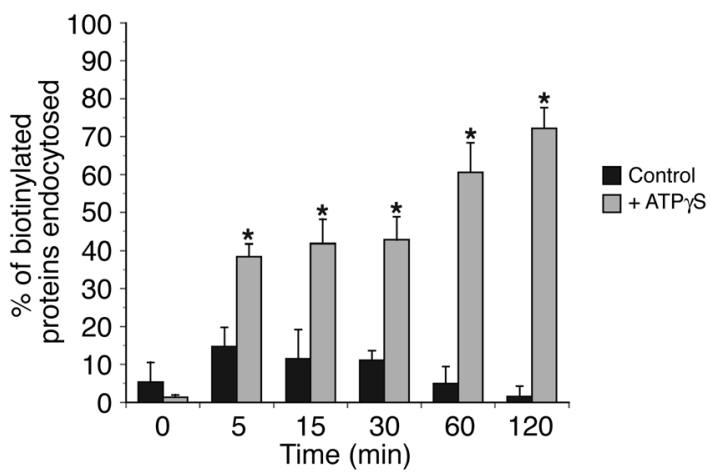

\section{Figure 4}

ATP $\gamma$ S-stimulated apical endocytosis in bladder umbrella cells. The apical surface of rabbit umbrella cells was biotinylated and then incubated for $0,5,15,30,60$, or 120 minutes in the absence (Control) or presence of $50 \mu \mathrm{M}$ ATP $\gamma$ S added to the serosal surface of the uroepithelium. In samples treated with ATP $\gamma$ S, the $t=0$ sample was taken immediately after addition of the agonist. The fraction of MESNA-protected biotinylated proteins was detected by probing Western blots with streptavidin-HRP, and the blots were quantified by densitometry. Data are expressed as mean \pm SEM $(n \geq 5)$. *Statistically significant difference $(P<0.05)$ relative to the appropriate control. The control data was published previously (26). 

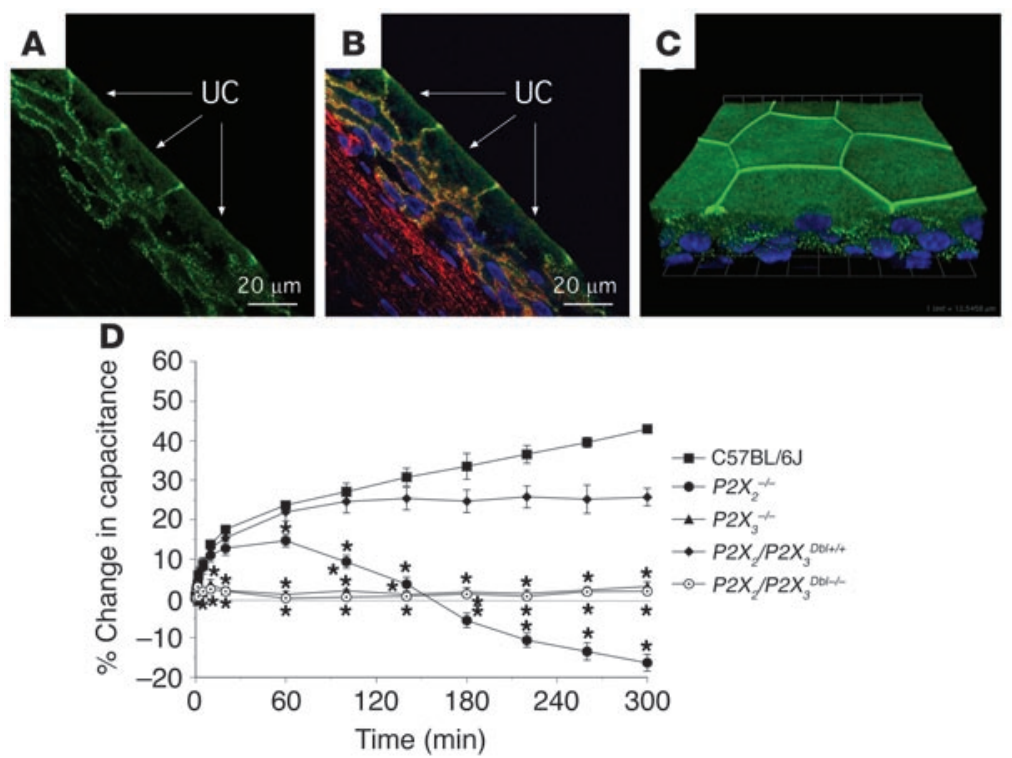

\section{Figure 5}

Localization of $\mathrm{P}_{2} \mathrm{X}_{3}$ in the uroepithelium and responses to pressure changes in $\mathrm{P} 2 \mathrm{X}_{2}$ - and $\mathrm{P} 2 \mathrm{X}_{3}$-knockout mice. ( $A$ and $\mathbf{B}$ ) Localization of $\mathrm{P} 2 \mathrm{X}_{3}$ in cryosections of rabbit bladder uroepithelium. (A) $\mathrm{P} 2 \mathrm{X}_{3}$ staining is shown in green, and the umbrella cells (UC) are marked with arrows. (B) Composite image with $\mathrm{P}_{2} \mathrm{X}_{3}$ staining shown in green, rhodamine-phalloidin-labeled actin in red, and Topro-3-labeled (Molecular Probes) nuclei in blue. (C) Whole mounted rabbit uroepithelium showing the distribution of the nuclei (blue) and $\mathrm{P} 2 \mathrm{X}_{3}$ (green). The image is a 3-dimensional reconstruction of a $Z$ series collected with a confocal microscope. The image was tilted around the $x$ axis to emphasize the 3-dimensional aspect of the image. The grid is a 3-dimensional scale bar, with each side of the square approximately equivalent to $12.5 \mu \mathrm{m}$. (D) Bladders from mice of the indicated strains were mounted in Ussing stretch chambers, the pressure was increased at $t=0$, and the capacitance was recorded. Data shown are mean \pm SEM $(n \geq 3)$. *Statistically significant difference $(P<0.05)$ relative to the appropriate control. added mucosally, while ADP again showed small effects ( 18\%) on capacitance (Table 1). Adenosine also caused a sizable increase in capacitance when added to the serosal surface ( $43 \%$; Table 1$)$ but smaller changes when added mucosally ( 18\%). AMP stimulated a significant increase in capacitance when added to either uroepithelial surface (serosal, $\sim 35 \%$; mucosal, $\sim 38 \%$ ). Taken together, these data suggest that multiple P2X, P2Y, and adenosine receptors may be involved in regulating changes in urothelial membrane capacitance and exocytosis. These data also suggest a unique spatial localization of purinergic receptor subtypes capable of mediating changes in capacitance through serosa or mucosa-dependent signaling events.

In addition to exocytosis, increased hydrostatic pressure stimulates apical endocytosis in umbrella cells (26), and the rates of endocytosis and exocytosis during bladder filling are such that the net effect is to add membrane. We previously reported that there is little endocytosis in the absence of stimulus (26). To test whether ATP affects endocytosis, we measured the internalization of biotinylated plasma membrane proteins upon addition of ATP $\gamma$ S to the serosal surface of the uroepithelium. ATP $\gamma \mathrm{S}$ caused a significant stimulation of apical endocytosis, with $72 \%$ of biotinylated proteins internalized after a 2-hour treatment with agonist (Figure 4). These data indicate that in addition to exocytosis, ATP may also modulate endocytosis in umbrella cells.

Receptors containing $\mathrm{P} 2 \mathrm{X}_{2}$ and $\mathrm{P} 2 \mathrm{X}_{3}$ subunits modulate pressureinduced exocytosis in umbrella cells. Previous data indicate that ATP activation of $\mathrm{P}_{2} \mathrm{X}_{3}$-containing receptors on subepithelial sensory nerve fibers controls bladder volume reflexes (21). However, the localization of $\mathrm{P} 2 \mathrm{X}_{2}$ and $\mathrm{P} 2 \mathrm{X}_{3}$ immunoreactivity within the uroepithelium $(15-17,23,25)$ suggests an additional sensory role for these receptors in regulating uroepithelial function. The pharmacological data presented above support the involvement of P2X receptors in regulating membrane exocytosis but are complicated by a lack of specific agonists/antagonists for individual P2X receptor subunits. In the present study, we observed $\mathrm{P} 2 \mathrm{X}_{3}$ localization along focal regions of the basolateral surface of rabbit umbrella cells and the plasma membrane of underlying cell layers (Figure 5, A and B), which is consistent with previous reports of
$\mathrm{P} 2 \mathrm{X}_{3}$ expression in the uroepithelium $(16,25)$. No staining was observed when antigenic peptide was included in the reactions (data not shown). Intriguingly, $\mathrm{P}_{2} \mathrm{X}_{3}$ staining was also observed below the apical plasma membrane and appeared to concentrate at the apicolateral region of the cell (Figure 5, A and B). We confirmed in whole-mounted tissue that $\mathrm{P} 2 \mathrm{X}_{3}$ circumscribed the apicolateral junction of the umbrella cell layer at or near the tight junction (Figure 5C); however, the significance of this localization is unknown. Unfortunately, we were unable to find antibodies that reliably stained for $\mathrm{P}_{2} \mathrm{X}_{3}$ in mouse uroepithelial tissues or $\mathrm{P} 2 \mathrm{X}_{2}$ in mouse and rabbit uroepithelial tissues.

To test whether $\mathrm{P} 2 \mathrm{X}_{2}$ and/or $\mathrm{P} 2 \mathrm{X}_{3}$ receptors were involved in pressure-induced exocytosis, we monitored membrane capacitance changes in bladders exposed to hydrostatic pressure from $\mathrm{P}_{2} \mathrm{X}_{2}$, $\mathrm{P} 2 \mathrm{X}_{3^{-}}$, and $\mathrm{P} 2 \mathrm{X}_{2} / \mathrm{P} 2 \mathrm{X}_{3}$-knockout mice and appropriate wild-type controls (Figure 5D). Increased pressure resulted in a significant increase in capacitance in bladders from C57BL/6J wild-type mice but had no effect on bladders from $P 2 X_{3}^{-/-}$mice (Figure 5D). $P 2 \mathrm{X}_{2}^{-{ }^{--}}$ mice showed a more complicated response to pressure, characterized by an initial rise in capacitance that decreased to approximately $20 \%$ less than the start value by 300 minutes (Figure 5D). In $\mathrm{P} 2 \mathrm{X}_{2}{ }^{-/} \mathrm{P} 2 \mathrm{X}_{3}{ }^{-/-}$mice, lacking both $\mathrm{P} 2 \mathrm{X}_{2}$ and $\mathrm{P} 2 \mathrm{X}_{3}$ receptor subunits, pressure-induced changes in capacitance were completely absent, despite pressure-induced capacitance changes in wild-type control $P 2 \mathrm{X}_{2}{ }^{+/+} \mathrm{P} 2 \mathrm{X}_{3}^{+/+}$mice. Consistent with previously reported findings (20), bladders from $P 2 X_{2}^{-/-}, P 2 X_{3}^{-/-}, P 2 X_{2}^{-/-} P 2 X_{3}^{-1-}$, and appropriate control mice released comparable levels of ATP when exposed to increased hydrostatic pressure (data not shown), which ruled out the trivial explanation that the defects observed in these mice were the consequence of failure to release ATP. In addition, bladders from both wild-type and P2X-knockout mice appeared by gross inspection to be similar in size, and scanning electron microscopy analysis of the surface of the umbrella cells showed similar-sized cells, with obvious tight junctions, and surfaces covered by plaques and hinges (data not shown).

We previously observed that increased hydrostatic pressure causes a decrease in the abundance of discoidal/fusiform vesicles found in the umbrella cell apical cytoplasm (26). Consistent with these 

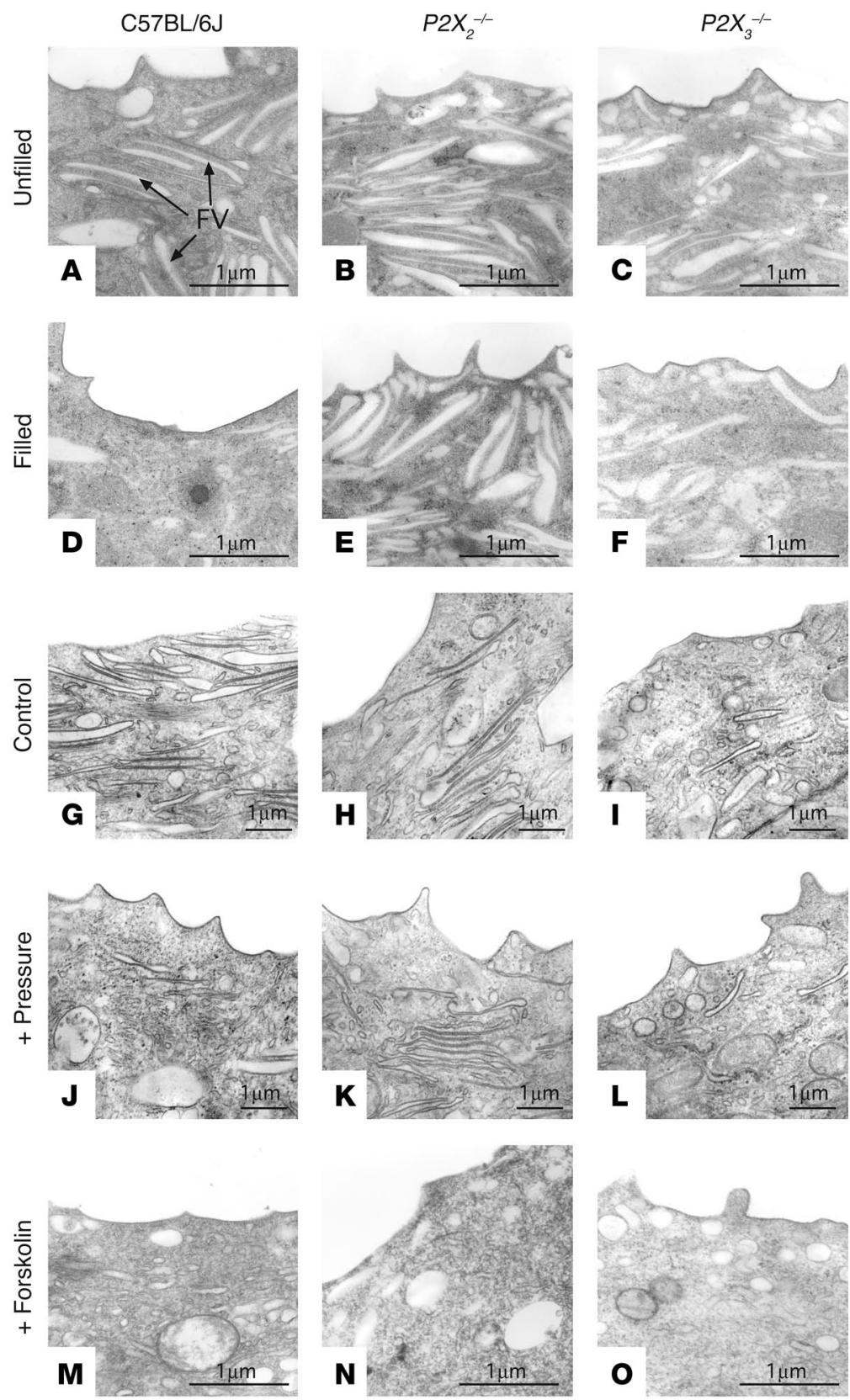

\section{Figure 6}

Transmission electron microscopy (TEM) analysis of apical pole of umbrella cells in wild-type and knockout mice. (A-F) C57BL/6J wild-type (A and D), $P 2 X_{2}{ }^{-1-}(\mathbf{B}$ and E), or $\mathrm{P}_{2} \mathrm{X}_{3}^{-1-}$ (C and $\mathbf{F}$ ) mice were catheterized, and the urine content of the bladder was drained. After a 30-minute incubation, the bladders were either excised and processed for TEM (A-C), or the bladder was slowly filled with normal saline at a rate of $1.4 \mu \mathrm{l} / \mathrm{min}$ for 180 minutes (D-F). Examples of fusiform vesicles (FV) are marked in $\mathbf{A}$. $(\mathbf{G}-\mathbf{O})$ TEM analysis of the apical poles of umbrella cells from C57BL/6J wild-type $(\mathbf{G}, \mathbf{J}$, and $\mathbf{M}), P 2 X_{2}^{-/-}(\mathbf{H}, \mathbf{K}$, and $\mathbf{N})$, or $P 2 X_{3}^{-/-}(\mathbf{I}, \mathbf{L}$, and $\mathbf{O})$ mice mounted in Ussing stretch chambers and incubated in the absence of hydrostatic pressure $(\mathbf{G}-\mathbf{I})$ or the presence of hydrostatic pressure $(\mathbf{J}-\mathbf{L})$ or treated with $10 \mu \mathrm{M}$ forskolin (added to the mucosal hemichamber) in the absence of pressure $(\mathbf{M}-\mathbf{O})$.

observations, slow filling of intact bladders of anesthetized mice (at a rate of $1.4 \mu \mathrm{l} / \mathrm{ml}$ ) resulted in an apparent decrease in the quantity of discoidal/fusiform vesicles in the apical cytoplasm of wild- type mice (compare Figure 6, A and D). However, little decrease was noted in the bladders from $P 2 X_{2}^{-1-}$ or $P 2 X_{3}^{-/-}$mice (compare Figure 6, B and $\mathrm{E}$ and Figure 6, $\mathrm{C}$ and $\mathrm{F}$ ). Bladders from $\mathrm{P}_{2} \mathrm{X}_{3}$-knockout mice have a greater volume threshold before increased pressure and voiding contractions are detected $(20,21)$, which is also true of the $\mathrm{P} 2 \mathrm{X}_{2}$-knockout mice (D. Cockayne, unpublished observations). Therefore, bladders from these mice were filled at a rate of $2.0-2.2 \mu \mathrm{l} / \mathrm{min}$ for 180 minutes. However, the results were similar, and little evidence of vesicle loss was noted in the knockout mice (data not shown). Similar results were obtained for mouse bladder tissue that was excised and mounted in Ussing stretch chambers (Figure 6, $\mathrm{G}-\mathrm{L}$ ). Decreased fusiform vesicles were observed in control mice exposed to pressure (compare Figure 6, G and $\mathrm{J}$ ), but no apparent change in fusiform vesicles was observed in $\mathrm{P}_{2} \mathrm{X}_{2}^{-{ }^{--}}$or $\mathrm{P}_{2} \mathrm{X}_{3}^{-{ }^{--}}$mice (compare Figure 6, $\mathrm{H}$ and $\mathrm{K}$ and Figure 6, I and L). These results are consistent with the hypothesis that $\mathrm{P} 2 \mathrm{X}_{3}$ - and $\mathrm{P} 2 \mathrm{X}_{2}$-containing receptors are involved in signaling exocytosis from the basolateral surface of the umbrella cells.

ATP-stimulated exocytosis is $\mathrm{Ca}^{2+}$ and PKA dependent. We previously demonstrated that exocytosis in umbrella cells is stimulated by agents that increase intracellular $\mathrm{Ca}^{2+}$ or cAMP production $(26,28)$. Upon ATP binding, $\mathrm{P} 2 \mathrm{X}$ receptor activation can result in increased levels of intracellular $\mathrm{Ca}^{2+}$, a result of $\mathrm{Ca}^{2+}$ influx from outside the cell and release of $\mathrm{Ca}^{2+}$ from intracellular stores (14, 42-44). Increased levels of intracellular $\mathrm{Ca}^{2+}$ can also activate some isoforms of adenylyl cyclase (45), resulting in increased cAMP production and activation of the cAMP effector PKA. Similarly, P2Y receptors, acting through heterotrimeric $G$ proteins, can also modulate the cytosolic concentrations of $\mathrm{Ca}^{2+}$ and cAMP

We sought to determine whether purinergic receptor activation mediated by ATP $\gamma \mathrm{S}$ stimulated exocytosis by a $\mathrm{Ca}^{2+}$-and/or cAMP-dependent pathway. As described above, serosal addition of $50 \mu \mathrm{M}$ ATP $\gamma \mathrm{S}$ in the absence of pressure caused a marked increase in capacitance of rabbit tissue. However, when tissue was treated with $50 \mu \mathrm{M}$ ATP $\gamma \mathrm{S}$ in nominally $\mathrm{Ca}^{2+}$ free Krebs solution, the change in capacitance was significantly inhibited (Figure 7). Similarly, when the uroepithelium was treated with serosal ATP $\gamma \mathrm{S}$ and $75 \mu \mathrm{M} 2$-aminoethoxydiphenylborate (APB), which inhibits $\mathrm{Ca}^{2+}$ release from inositol-1,4,5,triphosphate-dependent stores in the ER $(46,47)$, the capacitance increase was inhibited even further (Figure 7). Ryanodine $(50 \mu \mathrm{M})$, which prevents $\mathrm{Ca}^{2+}$ release from ryanodine-dependent stores when used at micromolar concentration (48), was less effective but did result in some decrease in ATP $\gamma$ S-stimulated changes in capacitance (Figure 7). Last, $10 \mu \mathrm{M} \mathrm{H89,}$ an inhibitor of PKA, also reduced ATP $\gamma$ S-stimulated changes in capacitance (Figure 7). These data indicate that second messenger cascades involving $\mathrm{Ca}^{2+}$ and cAMP may act downstream of purinergic receptor activation to stimulate exocytosis in umbrella cells. 


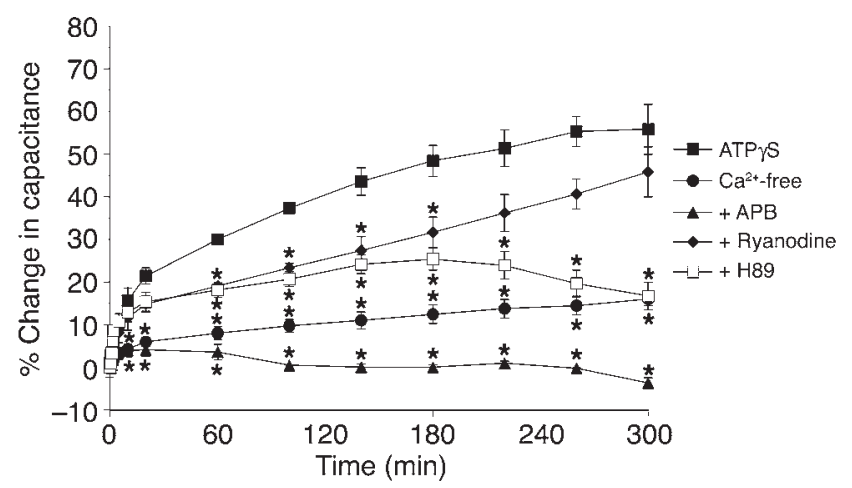

Figure 7

Potential role of $\mathrm{Ca}^{2+}$ and PKA in ATP $\gamma \mathrm{S}$-stimulated changes in membrane capacitance. Rabbit uroepithelium was mounted in modified Ussing chambers and preincubated with $75 \mu \mathrm{M}$ 2-aminoethoxydiphenylborate (APB), $50 \mu \mathrm{M}$ ryanodine, or $10 \mu \mathrm{M} \mathrm{H} 89$ for 30 minutes as indicated. In the $\mathrm{Ca}^{2+}$-free experiments, the normal Krebs solution was isovolumetrically replaced with Krebs solution lacking $\mathrm{Ca}^{2+}$. At $t=0,50 \mu \mathrm{M}$ ATP $\gamma \mathrm{S}$ was added into the serosal hemichamber, and changes in capacitance were monitored over time in the continued presence of the appropriate drug. Data are mean $\pm \operatorname{SEM}(n \geq 5)$. *Statistically significant difference $(P<0.05)$ relative to the ATP $\gamma S$ reaction.

Finally, if ATP binding acts as a proximal signal for membrane turnover, then one would predict that changes in membrane traffic could be stimulated by agents that increase the production of second messengers like cAMP, even in the $P 2 X_{2}^{-/-}$or $P 2 X_{3}^{-/-}$mice. We examined the morphology of wild-type C57BL/6J, $P 2 X_{2}^{-1-}$, and $P 2 X_{3}{ }^{-1-}$ mice exposed to forskolin. In control C57BL/6J mice, forskolin treatment resulted in an apparent loss of fusiform vesicles, consistent with vesicle fusion (compare Figure $6, \mathrm{G}$ and $\mathrm{M}$ ). A similar loss of vesicles was observed in $P 2 X_{2}^{-/-}$and $P 2 X_{3}^{-/-}$mice (compare Figure 6, $\mathrm{H}$ and $\mathrm{N}$ and Figure 6, I and O). These data are consistent with a model in which $\mathrm{P} 2 \mathrm{X}_{2}$ and $\mathrm{P} 2 \mathrm{X}_{3}$ subunit-containing receptors act upstream of second messenger cascades to regulate vesicle trafficking in umbrella cells.

\section{Discussion}

Contraction of the bladder detrusor smooth muscle and sensation of bladder filling are 2 aspects of bladder function that are regulated by purinergic receptor signaling pathways $(21,49,50)$. In this report, we present evidence that an additional role for these signaling pathways is to regulate membrane dynamics at the apical surface of the umbrella cell layer.

Pressure stimulates ATP release from the uroepithelium. We observed that ATP was released from both surfaces of isolated uroepithelium, with significantly more apparent ATP release from the mucosal surface. Ferguson et al. first reported that changes in hydrostatic pressure resulted in ATP release from the serosal, but not mucosal, surface of the bladder (22). However, our results are consistent with observations that ATP is released from the mucosal surface of uroepithelium in response to filling or perfusion $(7,20)$, and this process may be mediated by vesicular exocytosis (7). The mechanism of serosal ATP release is unknown but is stimulated by treatments that decrease the electrical potential difference across the epithelium (22). The actual concentration of ATP near the uroepithelial cell membranes is difficult to discern because of the relatively large volume of our chamber system, the multiple cell types underlying the umbrella cell layer, unstirred layer effects, and the action of tissue-associated ectonucleotidases/exonucleotidases that may have caused us to underestimate ATP release from either or both tissue surfaces. In fact, we observed that significant degradation of ATP occurs at the serosal surface of the tissue. While our results indicate that the epithelium is the primary source of ATP, there are scattered endothelial cells, fibroblasts, immune cells, and smooth muscle cells in the connective tissue underlying the epithelium that may contribute to the serosal ATP release in vivo.

ATP release from the bladder mucosa was sensitive to multiple pharmacological agents. BFA is a general inhibitor of secretion in several cell types including umbrella cells (26) and was the most potent inhibitor of ATP release in our system. Consistent with vesicular release, we observed large vesicular structures in the umbrella cell cytoplasm that labeled with quinacrine, an antimalarial acridine derivative binds avidly intracellular stores of $\operatorname{ATP}(6,51-53)$. The nature of the quinacrine-positive vesicles in umbrella cells is currently unknown. Alternatively, the BFA effect could be indirect and may reflect the altered cell surface delivery of proteins that might be necessary for ATP release, e.g., connexin hemichannels or transporters. This could explain why antagonists of other types of ATP release also had pronounced inhibitory effects. Anandamide and flufenamic acid, 2 frequently used antagonists of gap junction function $(8,32)$, inhibited ATP release, which possibly implicates connexin hemichannels in ATP release. Alternatively, the effect of anandamide and flufenamic acid could be indirect. Flufenamic acid blocks other channel types (54), while anandamide is a general inhibitor of secretion in neuronal cells and is a natural ligand for cannabinoid and TRPV1 receptors $(30,31)$, the latter of which we previously showed to be required for ATP release by the bladder uroepithelium (55). We also observed that verapamil and dipyridamole significantly impaired ATP release, which implicates $A B C$ and nucleoside transporters. However, verapamil acts on other targets including L-type $\mathrm{Ca}^{2+}$ channels (36). These latter results are in contrast to those of a previous study that found no effect of verapamil or dipyridamole on ATP release from guinea pig ureter epithelium (7) and may reflect species differences or differences in ureter versus bladder epithelium.

ATP binding to purinergic receptors is a proximal signal for umbrella cell exocytosis and endocytosis. Previous studies implicated the cytoskeleton, ATP (as an intracellular energy source), cAMP, $\mathrm{Ca}^{2+}$ signaling cascades, and possibly Rab27b and SNARE fusion components in discoidal/fusiform vesicle exocytosis $(26,28,56-58)$. However, a proximal signal(s) for exocytosis has yet to be described. In this report, we provide evidence that ATP, released from the serosal surface of the uroepithelium in response to changes in hydrostatic pressure, is one such signal. Data in support of this conclusion include the following. First, the addition of enzymes that hydrolyze extracellular ATP (e.g., apyrase or hexokinase/glucose) to the serosal hemichamber prevented increases in membrane capacitance in response to increased pressure. Second, the serosal addition of ATP or its analogs stimulated changes in capacitance in the absence of pressure changes. Third, forskolin caused an apparent loss of fusiform vesicles in $\mathrm{P}_{2} \mathrm{X}_{2}^{-{ }^{--}}$and $\mathrm{P} 2 \mathrm{X}_{3}^{-/-}$mice. Fourth, PPADS, a general inhibitor of purinergic receptors, inhibited pressure-associated changes in capacitance when added to the serosal hemichamber. Fifth, ATP analogs apparently acted upstream of a $\mathrm{Ca}^{2+}$ - and PKA-dependent second messenger cascade that stimulated exocytosis. 


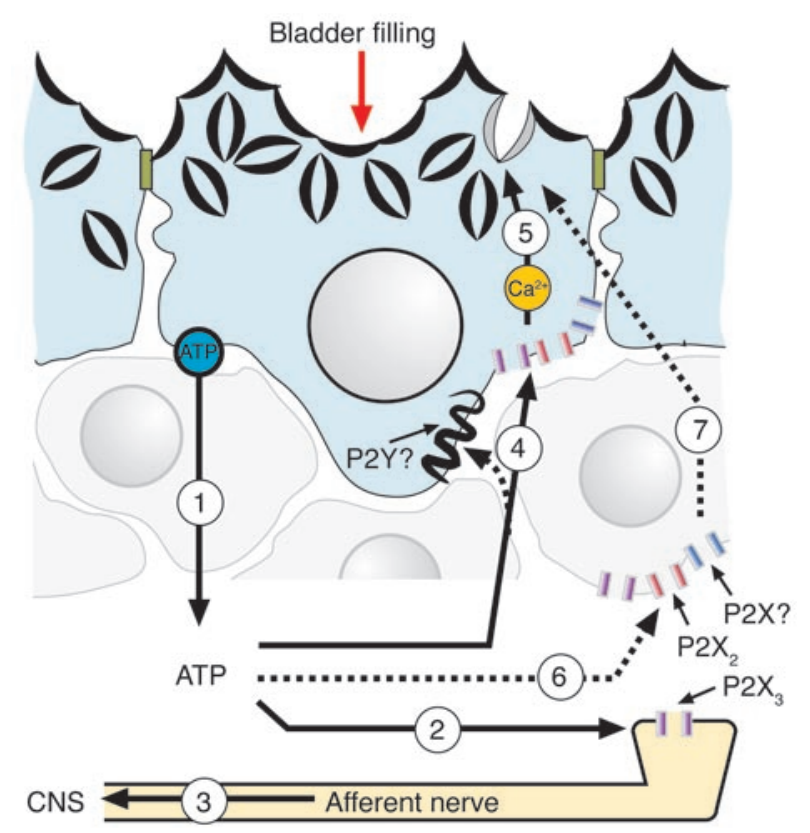

Figure 8

Model for ATP and purinergic receptor-regulated exocytosis/endocytosis in bladder umbrella cells. The accumulation of urine in the bladder increases hydrostatic pressure, stimulating release of ATP from uroepithelium (step 1) and possibly other adjacent cell types (not shown). ATP release may occur through multiple mechanisms, including vesicular release, conductance of ATP though $A B C$ or nucleoside transporters, or movement of ATP across connexin hemichannels. The serosally released ATP may bind to $\mathrm{P}_{2} \mathrm{X}_{3}$-containing receptors present on afferent nerve processes (step 2), increasing nerve firing and relaying bladder filling to the CNS (step 3). Serosally released ATP may also bind to receptors containing $\mathrm{P} 2 \mathrm{X}_{2}$ and/or $\mathrm{P}_{2} \mathrm{X}_{3}$ subunits present on the uroepithelium, including the basolateral surface of the umbrella cell layer (step 4). Other receptors, including P2X or P2Y receptor isoforms, are also present on the serosal surface of the epithelium and may also be stimulated by ATP (or other released or processed nucleotides/nucleosides). Ligand binding causes increased levels of cytoplasmic $\mathrm{Ca}^{2+}$ (a result of $\mathrm{Ca}^{2+}$ influx from outside the cell and efflux from intracellular stores) and activation of PKA that induces apical membrane turnover including discoidal/fusiform vesicle exocytosis and endocytosis (step 5). Although in the simplest model, ATP binds to purinergic receptors on the umbrella cell layer, it remains possible that ATP binds to purinergic receptors present on basal/intermediate cells (step 6), or other cell types, to signal the release of unidentified secretagogues that act upon umbrella cells to stimulate vesicle exocytosis (step 7). For simplicity, mucosal purinergic signaling events are not shown; however, these could be important in modulating the signaling pathways that initiate at the serosal surface of the umbrella cells.

In addition to stimulating exocytosis, increased hydrostatic pressure also stimulates endocytosis in the umbrella cells (26), but the signaling pathways regulating endocytosis under these conditions are unknown. The data from this study indicate that ATP released into the extracellular milieu may signal internalization of apical membrane proteins in umbrella cells. This is consistent with findings of recent studies in which ATP agonists resulted in the internalization of biotinylated $\mathrm{P} 2 \mathrm{X}_{1}$ receptors (59) and activation of a P2X $\mathrm{X}_{7}$-like receptor in thymocytes stimulated exocytosis and endocytosis (60). Similarly, endocytosis of P2Y receptors is stimulated by addition of uridine (61), and activation of $\mathrm{P} 2 \mathrm{Y}$ receptors may lead to endocytosis in prostate neuroendocrine cells (43). Although it is preliminary, we believe this to be the first evidence demonstrating that ATP signaling may be involved in regulation of pressure-induced endocytosis in bladder umbrella cells.

$P 2 X$ and $P 2 Y$ receptors modulate pressure-induced exocytosis in umbrella cells. Immunoreactivity for all $7 \mathrm{P} 2 \mathrm{X}$ receptor subtypes has now been identified in the bladder uroepithelium of human, rat, and cat $(15-17,23,25)$. However, the role that ionotropic ATP receptors such as $\mathrm{P} 2 \mathrm{X}_{3}$ might play in nonexcitable tissues such as the urothelium is not known. Our results indicate that 1 potential function of $\mathrm{P} 2 \mathrm{X}_{3}$-containing receptors is to modulate membrane dynamics at the apical pole of umbrella cells. Significantly, we observed that bladders from $P 2 X_{2}^{-/-}, P 2 X_{3}^{-/-}$, and $P 2 X_{2}^{-/-} P 2 X_{3^{-/-}}$ mice failed to show increases in membrane capacitance when exposed to hydrostatic pressure, despite pressure-induced capacitance changes in the appropriate wild-type controls. These data also provide what we believe to be the first evidence of a nonneuronal function for $\mathrm{P} 2 \mathrm{X} 3$ receptor subunits.

It was previously reported that $P 2 X_{3}^{-/-}$mice have an increased volume threshold before increased pressure and nerve firing is detected, which possibly indicates an increased bladder capacity $(20,21)$. If pressure-induced increases in umbrella cell surface area allow the bladder to hold increased volume, then one would predict that the knockout mice would have decreased bladder capacity. However, bladder capacity is a complex function of muscle tone, innervation, and mucosal surface area and is unlikely to simply reflect membrane dynamics in the umbrella cell layer. It is also possible that the membrane trafficking events we observe are important for maintaining the integrity of the apical surface and its function, but they may only play a minor role in modulating the storage capacity of the bladder. It is also worth noting that a lack of capacitance change in the $P 2 X_{3}^{-/-}$and $P 2 X_{2}^{-/-} P 2 X_{3}^{-1-}$ mice does not mean there is no exocytosis in the umbrella cells of these animals. Increases in capacitance are only observed if the rate of exocytosis is faster than the rate of endocytosis. If the rates of endocytosis/exocytosis were similar in the knockout animals, this could explain the apparently normal surface architecture of the mucosal surface of the knockout mice bladders.

Based on the data from our rabbit and mouse studies, the nature of the functional $\mathrm{P} 2 \mathrm{X}$ receptor involved in apical membrane trafficking is not entirely clear. $\alpha, \beta$-meATP, a potent agonist of homomeric $\mathrm{P} 2 \mathrm{X}_{3}$ and heteromeric $\mathrm{P} 2 \mathrm{X}_{2 / 3}$ receptors (14), had only modest effect in stimulating capacitance changes in rabbit uroepithelial tissue, which indicates that homomeric $\mathrm{P}_{2} \mathrm{X}_{3}$ or heteromeric $\mathrm{P} 2 \mathrm{X}_{2 / 3}$ receptors may not play a major role in pressure-stimulated membrane traffic in this tissue. Alternatively, the modest effect of $\alpha, \beta$-meATP may have been the consequence of $\alpha, \beta$-meATP-induced desensitization of the fast-inactivating homomeric $\mathrm{P} 2 \mathrm{X}_{3}$ channels (62). This rapid desensitization could prevent long-term capacitance responses. An alternative possibility is that $\mathrm{P}_{2} \mathrm{X}_{3}$ subunits are forming heteromultimeric channels with $\mathrm{P} 2 \mathrm{X}_{1}$ or $\mathrm{P} 2 \mathrm{X}_{5}$ subunits (63), poorly characterized channels that are likely to have properties distinct from those of $\mathrm{P}_{2} \mathrm{X}_{3}$ and $\mathrm{P} 2 \mathrm{X}_{2 / 3}$ receptors. A role for homomeric $\mathrm{P} 2 \mathrm{X}_{2}$ receptors within the uroepithelium is consistent with the data from experiments on the effects of various agonists in rabbit uroepithelium (significant stimulation by ATP $\gamma \mathrm{S}, \mathrm{ATP}$, and $2 \mathrm{MeSATP}$ but not $\alpha, \beta$-meATP) and with our findings that $\mathrm{P} 2 \mathrm{X}_{2}^{-/-}$mice had a decrease in apical membrane capacitance. Our observation that agonist-induced changes in capacitance occurred over a long period of time and 
required chronic stimulation with agonist might also be consistent with a role for $\mathrm{P} 2 \mathrm{X}_{2}$ receptors, since homomeric $\mathrm{P} 2 \mathrm{X}_{2}$ and heteromeric $\mathrm{P} 2 \mathrm{X}_{2 / 3}$ receptors are slowly desensitizing channels $(14,64)$. Like $\mathrm{P}_{2} \mathrm{X}_{3}$ subunits, $\mathrm{P} 2 \mathrm{X}_{2}$ subunits can form heteromultimeric channels with other $\mathrm{P} 2 \mathrm{X}$ subunits including $\mathrm{P} 2 \mathrm{X}_{1}, \mathrm{P} 2 \mathrm{X}_{5}$, and $\mathrm{P} 2 \mathrm{X}_{6}$ (63). Thus, it is possible that additional but less well-characterized heteromeric $\mathrm{P} 2 \mathrm{X}$ receptors may also play a role in modulating membrane traffic within the uroepithelium.

Although our data indicate that signaling pathways dependent on $\mathrm{P}_{2} \mathrm{X}_{2}$-and $\mathrm{P}_{2} \mathrm{X}_{3}$-containing receptors account for the majority of pressure-induced changes in membrane traffic, other purinergic signaling systems exist within the uroepithelium. 2MeSADP and 2MeSATP, which are potent agonists at several P2Y receptors (41) including $\mathrm{P}_{2} \mathrm{Y}_{1}$, caused significant increases in membrane capacitance when added to the serosal surface of the uroepithelium. ADP and UDP had intermediate effects, which further suggests a role for $\mathrm{P}_{2} \mathrm{Y}_{1}$ and $\mathrm{P} 2 \mathrm{Y}_{6}$ receptors. UTP, which is also a potent agonist at several P2Y receptors (37), caused a significant increase in membrane capacitance when added to the mucosal but not the serosal surface of the uroepithelium, which implicates $\mathrm{P}_{2} \mathrm{Y}_{2}$ or $\mathrm{P}_{2} \mathrm{Y}_{4}$ receptors in mucosal events (41). These data are consistent with the recent localization of $\mathrm{P} 2 \mathrm{Y}_{1}, \mathrm{P}_{2} \mathrm{Y}_{2}$, and $\mathrm{P} 2 \mathrm{Y}_{4}$ receptors in the cat uroepithelium (25). However, the lack of selective inhibitors of P2Y receptors made it difficult to assess the contribution of $\mathrm{P} 2 \mathrm{Y}$ receptors to the pressure-induced changes monitored in this study. We also observed that adenosine caused significant increases in capacitance when added to either cell surface. However, preliminary studies using P1 receptor antagonists and deaminase eliminated $\mathrm{P} 1$ receptors as significant players in signaling pressure-stimulated membrane traffic in the epithelium (our unpublished observations). Further work will be needed to define the function of P2Y or adenosine receptor cascades in normal uroepithelial function.

Model and summary. A common feature of the epithelial cells that line tube and sac organs such as blood vessels, the lungs, the gut, and the bladder is that they are mechanically sensitive and release ATP in response to physical stimuli $(2,3,61)$. ATP release controls diverse functions such as ion transport, beating of cilia, coordination of organ motility and contraction, and regulation of membrane dynamics $(2,3,61)$. In Figure 8 , we propose a model in which ATP also regulates membrane traffic at the apical pole of umbrella cells. This model expands on the previously described role for uroepithelially released ATP as a signal for bladder filling (21) and establishes ATP as a physiologically relevant upstream signal for altering apical membrane dynamics in umbrella cells. The large diversity of $\mathrm{P} 2$ receptors expressed by the uroepithelium suggests that other uroepithelial functions are regulated by purinergic signaling cascades, and these may provide important drug targets for bladder disorders such as interstitial cystitis, urge incontinence, outlet obstruction, and female idiopathic detrusor instability $(29,65-68)$, in which altered ATP release and P2 receptor expression has been described.

\section{Methods}

Reagents. Unless otherwise indicated, reagents were obtained from SigmaAldrich. Apyrase (grade II) was used at a final concentration of $0.4 \mathrm{U} / \mathrm{ml}$; hexokinase and glucose were used at final concentrations of $4 \mathrm{U} / \mathrm{ml}$ and $22 \mathrm{mM}$, respectively. Purinergic receptor agonists were prepared as 1,000-fold concentrated stocks in Krebs solution $(110 \mathrm{mM} \mathrm{NaCl}, 5.8 \mathrm{mM}$ $\mathrm{KCl}, 25 \mathrm{mM} \mathrm{NaHCO}_{3}, 1.2 \mathrm{mM} \mathrm{KH}_{2} \mathrm{PO}_{4}, 2.0 \mathrm{mM} \mathrm{CaCl}_{2}, 1.2 \mathrm{mM} \mathrm{MgSO}_{4}$, $11.1 \mathrm{mM}$ glucose) and diluted in Krebs solution just before use. The P2 inhibitor PPADS was dissolved in Krebs solution at $100 \mathrm{mM}$ and used at a final concentration of $100 \mu \mathrm{M}$. Guinea pig polyclonal antibodies to $\mathrm{P}_{2} \mathrm{X}_{3}$ were obtained from Neuromics Antibodies and were used at 1:500 to 1:1,000 dilution for immunohistochemistry.

Animals. Animals used in this study were female New Zealand White rabbits (3-4 kg; Myrtle's Rabbitry) and mice of the following strains (all females): $\mathrm{C} 57 \mathrm{BL} / 6 \mathrm{~J}$ control mice (Jackson Laboratory), congenic C57BL/ 6J.P2 $\mathrm{X}_{2}^{-/-}$mice (69), congenic C57BL/6J.P2 $\mathrm{X}_{3}^{-/-}$mice (21), $P 2 \mathrm{X}_{2}^{+/+} P 2 \mathrm{X}_{3}^{+/+}$

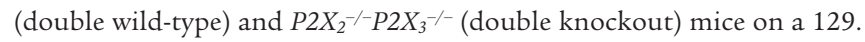
Ola $\times$ C57BL/6J mixed genetic background. Rabbits were euthanized by injection of $300 \mathrm{mg}$ sodium pentobarbital into the ear vein, while mice were euthanized by inhalation of $100 \% \mathrm{CO}_{2}$. Following euthanization and thoracotomy, the bladder was rapidly excised and processed as described below. P2X gene-knockout mice were bred at Roche Palo Alto with the approval of the Roche Palo Alto Institutional Use and Care Committee. All animal studies were carried out with the approval of the University of Pittsburgh Animal Care and Use Committee.

Mounting of uroepithelium in Ussing stretch chambers and measurement of tissue capacitance. Rabbit bladders were excised, and after careful dissection of the muscularis, the bladder mucosa was placed on tissue rings that exposed $2 \mathrm{~cm}^{2}$ of tissue as described previously (28). Mouse tissue was mounted on rings that exposed $0.35 \mathrm{~cm}^{2}$ of tissue. The tissue rings were mounted between 2 halves of a custom Ussing stretch chamber, each hemichamber was filled with $13 \mathrm{ml}$ Krebs solution, and the tissue was equilibrated for 30 minutes as described previously $(26,28)$. Bladder filling was mimicked by increasing hydrostatic pressure across the mucosal surface of the tissue by filling the mucosal hemichamber to a volume of $14 \mathrm{ml}$ (hemichamber capacity). For rabbit tissue, an additional $0.5 \mathrm{ml}$ of Krebs solution was injected by syringe into a Luer port to further increase the back pressure in the mucosal hemichamber $(26,28)$. We measured capacitance (where $1 \mu \mathrm{F} \approx 1 \mathrm{~cm}^{2}$ of membrane surface area) by monitoring the voltage response to a square current pulse, as described previously (26). Although the tissue preparations used in this study contained multiple cell layers, previous analysis confirmed that changes in capacitance primarily reflect changes in the apical surface area of the umbrella cell layer $(28,39,70)$.

Measurement of ATP release. Following mounting in Ussing stretch chambers and a 30-minute period of equilibration, the tissue was isovolumetrically washed 3 times with $60 \mathrm{ml}$ Krebs solution. Following an additional 30-minute incubation, hydrostatic pressure was increased as described above, and the aliquots were replaced with $200 \mu \mathrm{l}$ of Krebs solution from the serosal and mucosal hemichambers at the designated time points $(0,3$, $6,10,20,30,50$, and 60 minutes). ATP release was measured using a luciferin-luciferase ATP Bioluminescent Assay Kit (Sigma-Aldrich) according to the manufacturer's protocol. ATP was quantified in a TD-20/20 Luminometer (Turner BioSystems Inc.) programmed to inject the ATP assay mix. A standard curve was generated using known concentrations of ATP, and the data were reported as the ATP concentration in the Krebs solution bathing the mucosal or serosal surfaces of the tissue. In one series of experiments, the uroepithelium was carefully removed from the underlying submucosa by gentle scraping with a flexible cell scraper (model 83.1830; Sarstedt Inc.) (26). The remaining submucosa was mounted in the Ussing chamber, pressure was increased, and the release of ATP was monitored as described above. In some experiments, $50.0 \mu \mathrm{M}$ ATP was added to the mucosal or serosal hemichambers of washed tissue, and the amount of ATP remaining in the chambers was monitored over time. In control experiments, the tissue was replaced by plastic wrap.

Immunofluorescence and image acquisition. For cryosections, bladders from rabbits were fixed in $4 \%$ paraformaldehyde, $100 \mathrm{mM}$ sodium cacodylate buffer, $\mathrm{pH} 7.4$ for 2 hours at room temperature and prepared for immunofluorescence analysis, and images were collected using a TCS-SL 
confocal microscope (Leica Microsystems) as described previously (71). Whole-mounted tissue was similarly fixed and was prepared for confocal microscopic analysis as described previously (71). The Volocity program version 3.1 (Improvision) was used to project the confocal serial Z-series images into a single composite image or to generate 3-dimensional images. When appropriate, anti-P2 $\mathrm{X}_{3}$-antibodies were preincubated with antigenic peptide in block solution for 1 hour at $4^{\circ} \mathrm{C}$ on a rotator prior to tissue labeling. For quinacrine staining, isolated uroepithelium was incubated with $3 \mathrm{mM}$ quinacrine for 30 minutes at room temperature, the plasma membrane of the umbrella cells was labeled with $1 \mu \mathrm{M} \mathrm{N}$-(3-triethylammoniumpropyl)-4-(6-(4-(diethylamino)phenyl)hexatrienyl) pyridinium dibromide (FM4-64; Invitrogen Corp.) dissolved in Krebs solution, the tissue was mounted, and images were acquired using the confocal microscope.

Bladder filling and electron microscopy. Wild-type or knockout mice were anesthetized with urethane $(0.5 \mathrm{ml}$ of a $50 \mathrm{mg} / \mathrm{ml}$ aqueous solution $)$ and allowed to stabilize for 30 minutes. A suprapubic midline incision was made above the urethra, and the plastic jacket of a 24-g, three-quarter-inch IV catheter was trimmed to $12 \mathrm{~mm}$ and gently guided from the urethra into the bladder lumen, draining the urine content of the bladder. The incision insured proper placement of the catheter jacket, which helped to minimize catheter-induced epithelial damage. After a 30-minute incubation, the bladder was either excised and processed for transmission electron microscopy (TEM) or the it was slowly filled with normal saline at a rate of $1.4 \mu \mathrm{l} / \mathrm{min}$ for 180 minutes. In some experiments, bladders from the $\mathrm{P} 2 \mathrm{X}_{2}$ - and $\mathrm{P} 2 \mathrm{X}_{3}-\mathrm{knockout}$ mice were filled at a rate of $2.0-2.2 \mu \mathrm{l} / \mathrm{min}$ for 180 minutes. In all cases, the filled bladders were excised and processed for TEM. Fixation, embedding, sectioning, and electron microscopy were performed as described previously (72).

Cell surface biotinylation and measurement of endocytosis. The mucosal surface of bladder tissue, mounted and equilibrated as described above, was biotinylated as described previously (26). Briefly, $1 \mathrm{mg} / \mathrm{ml}$ of sulfo- $N$-hydroxysuccinimide-disulfo-biotin (Sulfo-NHS-SS-Biotin; Pierce Biotechnology Inc.), dissolved in ice-cold Krebs solution, was added to the mucosal hemichamber and incubated for 15 minutes on ice. The biotin/Krebs solution was aspirated, and fresh biotin in Krebs solution was added for another 15 minutes. The reaction was quenched by exchanging the apical solution with ice-cold minimal essential medium (Life Technologies, Inc.) containing $10 \%$ (vol/vol) FBS (HyClone) and washing 3 times for 15 minutes each time. The tissue (mounted in the chambers) was then returned to Krebs solution and equilibrated at $37^{\circ} \mathrm{C}$ for 30 minutes. Fifty micromolar ATP $\gamma$ was added to the serosal hemichamber for the indicated amount of time.
A 2-mercaptoethanesulfonic acid (MESNA) protection assay was used to measure endocytosis as described previously (26). Cell-surface biotin was removed by incubating the tissue for 30 minutes at $4{ }^{\circ} \mathrm{C}$ with $17 \mathrm{mg} / \mathrm{ml}$ MESNA in $50 \mathrm{mM}$ Tris $\mathrm{pH} 8.6,100 \mathrm{mM} \mathrm{NaCl}, 0.2 \% \mathrm{BSA}$, and 1 mM EDTA. The buffer was aspirated, and the reaction was quenched for 10 minutes at $4{ }^{\circ} \mathrm{C}$ with $25 \mathrm{mg} / \mathrm{ml}$ iodoacetic acid diluted in PBS. The iodoacetic acid was removed, and the tissue was washed 2 times with ice-cold Krebs solution. The chamber was disassembled and the apical surface was gently scraped to remove the uroepithelium. The scraped cells were placed in $150 \mu \mathrm{l}$ of $0.5 \%$ SDS-lysis buffer (containing $1 \mathrm{mM}$ phenylmethylsulfonyl fluoride). The samples were boiled for 5 minutes and then vortex shaken for 15 minutes at $4^{\circ} \mathrm{C}$. Protein lysate $(5 \mu \mathrm{g})$ was mixed with sample buffer lacking reducing agent, and the proteins were resolved on $15 \%$ SDS-polyacrylamide gels and transferred to Immobilon P membranes (Millipore), and biotinylated proteins were detected by incubating the membrane with streptavidin-HRP as described previously (26). The amount of endocytosis was calculated as the quotient of the signal intensity of the MESNA-treated lane and the untreated lane for each time point and was quantified by densitometry.

Statistical analysis. Statistically significant differences between means were determined by 2 -tailed Student's $t$ test, or when multiple comparisons were made, significant differences were assessed using ANOVA with the Bonferroni correction. $P<0.05$ was considered statistically significant.

\section{Acknowledgments}

We would like to thank Rebecca Hughey and Thomas Kleyman for their insightful comments and critiques during preparation of this manuscript. This work was supported by grants from the National Institute of Diabetes and Digestive Kidney Diseases and National Institute for Biomedical Imaging and Bioengineering of the NIH to E.C.Y. Wang (T32-DK61296), E.M. Balestreire (F31-EB005145-01), L.A. Birder (RO1-DK54824 and RO1-DK57284), and G. Apodaca (R37-DK54425). The Laboratory of Epithelial Cell Biology is supported in part by an equipment grant from Dialysis Clinic Inc.

Received for publication December 2, 2004, and accepted in revised form June 7, 2005.

Address correspondence to: Gerard Apodaca, University of Pittsburgh, Renal Division, 982 Scaife Hall, 3550 Terrace Street, Pittsburgh, Pennsylvania 15261, USA. Phone: (412) 383-8893; Fax: (412) 383-8955 or (412) 383-8956; E-mail: gla6@pitt.edu.
1. Novak, I. 2003. ATP as a signaling molecule: the exocrine focus [review]. News Physiol. Sci. 18:12-17.

2. Burnstock, G. 2001. Purine-mediated signalling in pain and visceral perception. Trends Pharmacol. Sci. 22:182-188.

3. Cooke, H.J., Wunderlich, J., and Christofi, F.L. 2003. "The force be with you": ATP in gut mechanosensory transduction [review]. News Physiol. Sci. 18:43-49.

4. Sorensen, C.E., and Novak, I. 2001. Visualization of ATP release in pancreatic acini in response to cholinergic stimulus. Use of fluorescent probes and confocal microscopy. J. Biol. Chem. 276:32925-32932.

5. Maroto, R., and Hamill, O.P. 2001. Brefeldin A block of integrin-dependent mechanosensitive ATP release from Xenopus oocytes reveals a novel mechanism of mechanotransduction. J. Biol. Chem. 276:23867-23872.

6. Bodin, P., and Burnstock, G. 2001. Evidence that release of adenosine triphosphate from endothelial cells during increased shear stress is vesicular. J. Cardiovasc. Pharmacol. 38:900-908.
7. Knight, G.E., Bodin, P., de Groat, W.C., and Burnstock, G. 2002. ATP is released from guinea pig ureter epithelium on distention. Am. J. Physiol. 282:F281-F288.

8. Stout, C.E., Costantin, J.L., Naus, C.C.G., and Charles, A.C. 2002. Intercellular calcium signaling in astrocytes via ATP release through connexin hemichannels. J. Biol. Chem. 277:10482-10488.

9. Reisin, I.L., et al. 1994. The cystic fibrosis transmembrane conductance regulator is a dual ATP and chloride channel. J. Biol. Chem. 269:20584-20591.

10. Schweibert, E.M., et al. 1995. CFTR regulates outwardly rectifying chloride channels through an autocrine mechanism involving ATP. Cell. 81:1063-1073.

11. Grygorczyk, R., and Hanrahan, J.W. 1997. CFTRindependent ATP release from epithelial cells triggered by mechanical stimuli. Am. J. Physiol. Cell Physiol. 272:C1058-C1066.

12. Watt, W.C., Lazarowski, E.R., and Boucher, R.C. 1998. Cystic fibrosis transmembrane regulator-independent release of ATP. J. Biol. Chem. 273:14053-14058.
13. Shaver, S.R. 2001. P2Y receptors: biological advances and therapeutic opportunities [review]. Curr. Opin. Drug Discov. Devel. 4:665-670.

14. North, R.A. 2002. Molecular physiology of P2X receptors. Physiol. Rev. 82:1013-1067.

15. Lee, H.Y., Bardini, M., and Burnstock, G. 2000. Distribution of $\mathrm{P} 2 \mathrm{X}$ receptors in the urinary bladder and the ureter of the rat. J. Urol. 163:2002-2007.

16. Elneil, S., Skepper, J.N., Kidd, E.J., Williamson, J.G., and Ferguson, D.R. 2001. Distribution of $\mathrm{P} 2 \mathrm{X}_{1}$ and $\mathrm{P}_{2} \mathrm{X}_{3}$ receptors in the rat and human urinary bladder. Pharmacology. 63:120-128.

17. Vial, C., and Evans, R.J. 2000. P2X receptor expression in mouse urinary bladder and the requirement of $\mathrm{P} 2 \mathrm{X}_{1}$ receptors for functional $\mathrm{P} 2 \mathrm{X}$ receptor responses in the mouse urinary bladder smooth muscle. Br. J. Pharmacol. 131:1489-1495.

18. Brown, C., Burnstock, G., and Cocks, T. 1979. Effects of adenosine-5-triphophate (ATP) and betagamma-methylene ATP on the rat urinary bladder. Br. J. Pharmacol. 65:97-102.

19. King, J.A., Huddart, H., and Staff, W.G. 1997. Purinergic modulation of rat urinary bladder detrusor 
smooth muscle. Gen. Pharmacol. 29:597-604.

20. Vlaskovska, M., et al. 2001. P2X $\mathrm{X}_{3}$ knock-out mice reveal a major sensory role for urothelially released ATP. J. Neurosci. 21:5670-5677.

21. Cockayne, D.A., et al. 2000. Urinary bladder hyporeflexia and reduced pain-related behaviour in P2X 3 -deficient mice. Nature. 407:1011-1015.

22. Ferguson, D.R., Kennedy, I., and Burton, T.J. 1997. ATP is released from rabbit urinary bladder epithelial cells by hydrostatic pressure changes - a possible sensory mechanism? J. Physiol. 505:503-511.

23. Tempest, H.V., et al. 2004. $\mathrm{P} 2 \mathrm{X}_{2}$ and $\mathrm{P} 2 \mathrm{X}_{3}$ receptor expression in human bladder urothelium and changes in interstitial cystitis. BJU Int. 93:1344-1348.

24. Sun, Y., and Chai, T.C. 2004. Up-regulation of $\mathrm{P}_{2} \mathrm{X}_{3}$ receptor during stretch of bladder urothelial cells from patients with interstitial cystitis. J. Urol. 171:448-452.

25. Birder, L.A., et al. 2004. Alterations in P2X and P2Y purinergic receptor expression in urinary bladder from normal cats and cats with interstitial cystitis. Am. J. Physiol. 287:F1084-F1091.

26. Truschel, S.T., et al. 2002. Stretch-regulated exocytosis/endocytosis in bladder umbrella cells. Mol. Biol. Cell. 13:830-846.

27. Apodaca, G. 2004. The uroepithelium: not just a passive barrier [review]. Traffic. 5:1-12.

28. Wang, E., Truschel, S.T., and Apodaca, G. 2003 Analysis of hydrostatic pressure-induced changes in umbrella cell surface area. Methods. 30:207-217.

29. Birder, L.A., et al. 2003. Feline interstitial cystitis results in mechanical hypersensitivity and altered ATP release from bladder urothelium. Am. J. Physiol. 285:F423-F429.

30. D’Amico, M., Cannizzaro, C., Preziosi, P., and Martire, M. 2004. Inhibition by anandamide and synthetic cannabimimetics of the release of $\left[{ }^{3} \mathrm{H}\right] \mathrm{D}$ aspartate and $\left[{ }^{3} \mathrm{H}\right]$ GABA from synaptosomes isolated from the rat hippocampus. Neurochem. Res. 29:1553-1561.

31. Izzo, A.A., Mascolo, N., and Capasso, F. 2001. The gastrointestinal pharmacology of cannabinoids. Curr. Opin. Pharmacol. 1:597-603.

32. Coco, S., et al. 2003. Storage and release of ATP from astrocytes in culture. J. Biol. Chem. 278:1354-1362.

33. Sheppard, D.N., and Welsh, M.J. 1992. Effect of ATP-sensitive $\mathrm{K}+$ channel regulators on cystic fibrosis transmembrane conductance regulator chloride currents. J. Gen. Physiol. 100:573-591.

34. Fosset, M., de Weille, J.R., Green, R.D, SchmidAntomarchi, H., and Lazdunski, M. 1988. Antidiabetic sulfonylureas control action potential properties in heart cells via high affinity receptors that are linked to ATP-dependent $\mathrm{K}+$ channels. J. Biol. Chem. 263:7933-7936.

35. Demolombe, S., and Escande, D. 1996. ATP-binding cassette proteins as targets for drug discovery. Trends Pharmacol. Sci. 17:273-275.

36. Triggle, D.J. 2003. Drug targets in the voltage-gated calcium channel family: why some are and some are not [review]. Assay Drug Dev. Technol. 1:719-733.

37. Bernhardt, I., et al. 1999. Characterization of the $\mathrm{K}^{+}\left(\mathrm{Na}^{+}\right) / \mathrm{H}^{+}$monovalent cation exchanger in the human red blood cell membrane: effects of transport inhibitors. Gen. Physiol. Biophys. 18:119-137.

38. Lazarowski, E.R., Boucher, R.C., and Harden, T.K.
2003. Mechanisms of release of nucleotides and integration of their action as P2X-and P2Y-receptor activating molecules. Mol. Pharmacol. 64:785-795.

39. Lewis, S., and de Moura, J. 1984. Apical membrane area of rabbit urinary bladder increases by fusion of intracellular vesicle: an electrophysiological study. J. Membr. Biol. 82:123-136.

40. Bianchi, B.R., et al. 1999. Pharmacological characterization of recombinant human and rat P2X receptor subtypes. Eur. J. Pharmacol. 376:127-138.

41. Sak, K., and Webb, T.E. 2002. A retrospective of recombinant $\mathrm{P} 2 \mathrm{Y}$ receptor subtypes and their pharmacology. Arch. Biochem. Biophys. 397:131-136.

42. Osipchuk, Y., and Cahalan, M. 1992. Cell-to-cell spread of calcium signals mediated by ATP receptors in mast cells. Nature. 359:241-244.

43. Kim, J.H., et al. 2004. Purinergic receptors coupled to intracellular $\mathrm{Ca}^{2+}$ signals and exocytosis in rat prostate neuroendocrine cells. J. Biol. Chem. 279:27345-27356

44. Xia, S.-L., et al. 2004. Extracellular ATP-induced calcium signaling in mIMCD-3 cells requires both P2X and P2Y purinoceptors. Am. J. Physiol. 287:F204-F214.

45. Hanoune, J., and Defer, N. 2001. Regulation and role of adenylyl cyclase isoforms. Annu. Rev. Pharmacol. Toxicol. 41:145-174.

46. Ma, H.-T., Venkatachalam, K., Parys, J.B., and Gill, D.L. 2002. Modification of store-operated channel coupling and inositol trisphosphate receptor function by 2-aminoethoxydiphenyl borate in DT40 lymphocytes. J. Biol. Chem. 277:6915-6922.

47. Maruyama, T., Kanaji, T., Nakade, S., Kanno, T. and Mikoshiba, K. 1997. 2APB, 2-aminoethoxydiphenyl borate, a membrane-penetrable modulator of Ins $(1,4,5) \mathrm{P} 3$-induced $\mathrm{Ca}^{2+}$ release. J. Biochem. 122:498-505.

48. Sutko, J.L., Airey, J.A., Welch, W., and Ruest, L. 1997. The pharmacology of ryanodine and related compounds. Pharmacol. Rev. 49:53-98.

49. McMurray, G., Dass, N., and Brading, A.F. 1998. Purinoceptor subtypes mediating contraction and relaxation of marmoset urinary bladder smooth muscle. Br. J. Pharmacol. 123:1579-1586.

50. Fujii, K. 1988. Evidence for adenosine triphosphate as an excitatory transmitter in guinea pig, rabbit and pig urinary bladder. J. Physiol. 404:39-52.

51. Mitchell, C.H., Carre, D.A., and McGlinn, A.M. 1998. A release mechanism for stored ATP in ocular ciliary epithelial cells. Proc. Natl. Acad. Sci. U. S. A. 95:7174-7178

52. Irvin, J.L., and Irvin, E.M. 1954. The interaction of quinacrine with adenine nucleotides. J. Biol. Chem. 210:45-56.

53. Olson, L., Alund, M., and Norberg, K.A. 1976 Fluorescence-microscopical demonstration of a population of gastrointestinal nerve fibers with a selective affinity for quinacrine. Cell Tissue Res. 171:407-423

54. Hill, K., Benham, C.D., McNulty, S., and Randall, A.D. 2004. Flufenamic acid is a pH-dependent antagonist of TRPM2 channels. Neuropharmacology. 47:450-460.

55. Birder, L.A., et al. 2002. Altered urinary bladder function in mice lacking the vanilloid receptor TRPV1. Nat. Neurosci. 5:856-860.

56. Chen, Y., et al. 2003. Rab27b is associated with fusiform vesicles and may be involved in targeting uroplakins to urothelial apical membranes. Proc. Natl. Acad. Sci. U. S. A. 100:14012-14017.

57. Born, M., Pahner, I., Ahnert-Hilger, G., and Jons, T. 2003. The maintenance of the permeability barrier of bladder facet cells requires a continuous fusion of discoidal vesicles with the apical plasma membrane. Eur. J. Cell Biol. 82:343-350.

58. Sarikas, S., and Chlapowski, F. 1986. Effect of ATP inhibitors on the translocation of luminal membrane between cytoplasm and cell surface of transitional epithelial cells during the expansion-contraction cycle of the rat urinary bladder. Cell Tissue Res. 246:109-117.

59. Ennion, S.J., and Evans, R.J. 2001. Agoniststimulated internalization of the ligand-gated ion channel $\mathrm{P} 2 \mathrm{X}_{1}$ in rat vas deferens. FEBS Lett. 489:154-158.

60. Kochukov, M.Y., and Ritchie, A.K. 2005. P2X7 receptor stimulation of membrane internalization in a thyrocyte cell line. J. Membr. Biol. 204:11-21.

61. Brinson, A.E., and Harden, T.K. 2001. Differential regulation of the uridine nucleotide-activated $\mathrm{P}_{2} \mathrm{Y}_{4}$ and $\mathrm{P}_{2} \mathrm{Y}_{6}$ receptors. J. Biol. Chem. 276:11939-11948.

62. Virginio, C., Robertson, G., Surprenant, A., and North, R.A. 1998. Trinitrophenyl-substituted nucleotides are potent antagonists selective for $\mathrm{P} 2 \mathrm{X}_{1}, \mathrm{P} 2 \mathrm{X}_{3}$, and heteromeric $\mathrm{P} 2 \mathrm{X}_{2 / 3}$ receptors. Mol. Pharmacol. 53:969-973.

63. Torres, G.E., Egan, T.M., and Voigt, M.M. 1999. Hetero-oligomeric assembly of $\mathrm{P} 2 \mathrm{X}$ receptor subunits. Specificities exist with regard to possible partners. J. Biol. Chem. 274:6653-6659.

64. Lewis, C., et al. 1995. Coexpression of $\mathrm{P} 2 \mathrm{X}_{2}$ and $\mathrm{P} 2 \mathrm{X}_{3}$ receptor subunits can account for ATP-gated currents in sensory neurons. Nature. 377:432-435.

65. Moore, K.H., Ray, F.R., and Barden, J.A. 2001. Loss of purinergic $\mathrm{P}_{2} \mathrm{X}_{3}$ and $\mathrm{P} 2 \mathrm{X}_{5}$ receptor innervation in human detrusor from adults with urge incontinence. J. Neurol. 21:RC1661-RC1666.

66. O'Reilly, B.A., et al. 2001. A quantitative analysis of purinoceptor expression in the bladders of patients with symptomatic outlet obstruction. Br. J. Urol. 87:617-622.

67. O'Reilly, B.A., et al. 2002. P2X receptors and their role in female idiopathic detrusor instability. J. Urol. 167:157-164.

68. Sun, Y., Keay, S., DeDeyne, P., and Chai, T.C. 2001. Augmented stretch activated adenosine triphosphate release from bladder uroepithelial cells in patients with interstitial cystitis. J. Urol. 166:1951-1956.

69. Rong, W., et al. 2003. Pivotal role of nucleotide $\mathrm{P} 2 \mathrm{X}_{2}$ receptor subunit of the ATP-gated ion channel mediating ventilatory responses to hypoxia. J. Neurosci. 23:11315-11321.

70. Clausen, C., Lewis, S.A., and Diamond, J.M. 1979. Impedance analysis of a tight epithelium using a distributed resistance model. Biophys. J. 26:291-318.

71. Acharya, P., et al. 2003. Distribution of the tight junction proteins $\mathrm{ZO}-1$, occludin, and claudin-4, -8 , and -12 in bladder epithelium. Am. J. Physiol. 287:F305-F318.

72. Apodaca, G., et al. 2003. Disruption of bladder epithelium barrier function after spinal cord injury. Am. J. Physiol. 284:F966-F976. 